\title{
HERENCIA PICARESCA Y MESTIZAJE EN AMÉRICA LATINA
}

\author{
Nelson Vallejo-Gómez ${ }^{1}$
}

"No somos indios ni europeos, sino una especie media"

Bolivar (1819)

La marca de identidad latinoamericana en el mundo globalizado es la de ser mestizo, pero también la de ser "vivo", rebuscador y transgresor. Por lo mismo, la acepción mestizo conlleva una connotación negativa. Veo en la herencia de tipo picaresco el origen de tal negatividad; lo cual requiere ser explorado, en busca de la diversidad de sentidos que tiene, pues hay marca de España y también emergencias inéditas, propias al Nuevo Mundo.

Propongo entonces indagar a través de una intuición literaria que muestre, en su antropología, el carácter fasto y nefasto de la herencia picaresca de corte castellano, mutado en viveza criolla. La hipótesis de trabajo es que una comprensión positiva de lo que se entiende en propio por mestizaje latinoamericano trasciende los aportes de la picardía castellana, la malicia indígena y la viveza criolla. Con lo cual esclarece la sombra contradictoria que colabora en la estructuración de la identidad del subcontinente, desde el Rio Grande en el Norte, hasta el Rio de la Plata en el Sur, pasando por los países andinos.

1 Bachiller del Liceo de la Universidad de Antioquia, Diplomado en Licenciatura, Maestría y Especialización en Filosofía Moderna y Contemporánea por la Universidad de la Sorbona-Paris IV, Doctor Honoris Causa por la Universidad de Caldas (Manizales), la Universidad Nacional de Cajamarca y la Universidad Ricardo Palma (Perú). Director científico del Programa PREFALC y Co-director del Laboratorio en ciencias humanas y sociales, GRECOL-ALC, en la Fondation Maison des Sciences de l'Homme (Paris). http://www.fmsh.fr/fr/recherche/24250, blog personal: www.nelsonvallejogomez.org 
Como el caudillo en política, la viveza criolla es el avatar en el Nuevo Mundo de la picardía castellana, cierta entrada por atajo a lo universal. Lo cual trastoca la servidumbre por origen y vislumbra la posibilidad de pervertirla o de marcar en la sombra una mueca irónica, una revuelta contra la opresión colonial. La picardía es un bosquejo de libre albedrio, es la marca de un cambio de sociedad y de paradigma, es la inclusión del reconocimiento por el mérito propio, en negativo por cierto, u otro tipo de linaje posible.

Una serie de interrogantes dolorosos y perversos conducen esta indagación: ¿hasta cuándo seguirá siendo lo picaresco de corte castellano, mutado en viveza criolla, patente de corso a la bellaquería, a la violación de la ley o a la transgresión más o menos refinada? ¿Podría el mestizaje ladino, como marca valorativa, trascender la herencia picaresca y la viveza criolla, y así reconocido como identidad meridional, ser pregonero en la era planetaria de una ética compleja que contemple el tercio excluido en positivo, promueva la justicia con responsabilidad y solidaridad, legalidad y legitimidad? ¿Podría la imagen del mestizo latinoamericano contribuir por medios reales y virtuales a que cese la parodia de un continente en donde se da tradicionalmente gato por liebre, ensayo por realización y transgresión por paradigma? ¿Podría América latina y en el archipiélago del Caribe transmitir al mundo un mensaje con perspectiva de futuro e identidad propia, un mensaje que contribuya a una política de civilización y de inclusión, al reconocimiento de un mundo multipolar e interdependiente, un mundo en donde el entramado intercultural mestizo sea una identidad abierta y serena, en donde el mestizaje latinoamericano contenga un envío que contribuya a la humanización en la era planetaria, a la toma de conciencia por doquier de la identidad humana como universal concreto? En suma: ¿Cuál es la marca latinoamericana o contribución de esta región del mundo a la antropología filosófica de la identidad planetaria? 
Entre los descendientes de los conquistadores afincados en territorio americano, lejos de España, la llamada por los criollos "madre patria", se establece un primer proceso de identidad mixta, una nueva crianza. En Certidumbre de América, Arrom (1971) precisa que el vocablo "criollo" surgiría por primera vez en un oficio real peruano de 1567, en donde se lo emplea para distinguir a un grupo de españoles: "estos que acá han nacido". Otros documentos establecen una diferencia entre los "acá nacidos" provenientes de Portugal o de África como "negro criollo", o de Asía, "chino criollo", o a los nacidos en América, África y Asia respectivamente. Por su lado, en La aparición de la conciencia criolla en el Virreinato del Perú -Antagonismo hispano - criollo en las órdenes religiosas del siglo XVI y XVII- (1982), Bernard Lavallé estudia la arqueología del criollo, las contradicciones de la "conciencia criolla".

Hay, en esa conciencia en busca de identidad y raíces en el Nuevo Mundo, un juego narrativo de poderes en conflicto, de afectos en reivindicación. En Narraciones de la independencia, Scavino nos invita a entender mejor las causas de estas identificaciones antitéticas, de esta "conciencia en proceso o espíritu criollo", si recordamos que se trata de "efectos imaginarios de dos mitos que los integrantes de esta minoría (los criollos) cuentan, protagonizan y escuchan desde su más tierna infancia" (2010, p.21). Según Scavino, el relato de la independencia de las Colonias españolas en América es un relato criollo; los criollos son quienes piensan y establecen la narración de la Independencia. Por prueba, Simón Bolivar, criollo por antonomasia, es quien concretiza dicha identidad en la "Carta de Jamaica" y en el "Discurso Inaugural del Congreso de Angostura" (1815-1819), donde la narración de tipo criollo es la de un "americano meridional". La "Carta de Jamaica" responde a la pregunta de un inglés (Henry Cullen) sobre la suerte futura y los verdaderos proyectos de aquellos individuos que se quieren independizar de España. ¿ "Cuál es la suerte futura y los verdaderos proyectos" de los habitantes de América? He aquí una pregunta política clave para naciones autónomas e independientes. Bolívar la formuló hace dos siglos. 
Tratándose de una pregunta de cara al futuro, "solo se pueden ofrecer conjeturas más o menos aproximativas", precisa el Libertador, con una prudencia propia al espíritu mestizo que lo animaba. Ya era claro que los americanos tenían que construir su "propio futuro", es decir, tenían que enfrentar la Modernidad, así no estuviesen preparados.

A cada cual toca construir lo propio, cuando ya está encontrado, cuando entra en Modernidad. Tratase ahí de una militancia propia del oprimido, en busca de identidad. Tal es la marca de la utopía bolivariana. "La América está encontrada entre sí, dice Bolívar, pero su situación, como la de sus habitantes, en los albores de la independencia, es la de infantes rodeados de incertidumbre, ignorancia y error". ¿Qué suerte futura y qué verdaderos proyectos en la situación de "infantes rodeados de ignorancia e incertidumbre"? "En mi concepto - dice Bolivar, esta es la imagen de nuestra situación, comparando el desplomado Imperio Español y el Romano, con la diferencia de que las nuevas naciones americanas apenas conservan vestigios del pasado - no era el caso de los pueblos que integraban el Imperio Romano, que traían individuos con historias de varios siglos-, y que nosotros". Bolívar no tiene ni tendrá conciencia de la riqueza cultural de los pueblos precolombinos de los andes o de los valles mexicanos. Pero lo que importa es que aquí, por primera vez, de manera muy precisa, en la "Carta de Jamaica", se bosqueja ese "Nosotros" de majestad, y muy ambiguo porque está en juego la imagen y el relato sociológico de los criollos, que no son ni españoles ni americanos, de los españoles, pero también de los indios y los africanos. ¿Quién designa entonces ese "¿Nosotros", tan poco identificable como tal? El proyecto de la relación de la independencia es un proyecto de un conjunto, de una identidad unida en su diversidad, de un "Nosotros". Por otra parte -y es aquí donde queda una pregunta en suspenso, Bolívar precisa que ese "Nosotros" no designa los naturales, indígenas o indios, ni tampoco los españoles o europeos, sino una especie media -la del "meridional" que se encuentra, precisa el Libertador, "entre los legítimos propietarios del país (los indígenas) 
y los usurpadores españoles (los conquistadores)". Para Bolívar no hay sincretismo. En lo dicho hasta ahora, resuena el tema de la identidad del mestizo latinoamericano que, encontrado, deberá asumir su propia identidad, que se ha ido constituyendo, como dice Hugo Neira, "a contragolpe".

Identidad es una urdimbre con hilos de muchos colores y, sobre todo, con dinámica creativa y fecunda. La verdadera identidad no es uno ni la multiplicación de lo uno, porque uno por uno siempre es y da uno, sino la suma de lo uno que con otro uno, son dos. Identidad es, como dice Octavio Paz (1957): "hambre de ser, oh muerte, pan de todos". Y unos veros antes, Paz precisa una metafísica de la identidad, que podríamos llamar de corte meridional, mestiza y latinoamericana: "para que pueda ser he de ser otro, / salir de mí, buscarme entre los otros, / los otros que no son si yo no existo, / los otros que me dan plena existencia". Desde finales del siglo XVIII, y con las corrientes intelectuales de la ilustración europea, en particular la de pensadores como Montaigne, Pascal, Descartes, Rousseau, la pregunta por el individuo, solo y en sociedad, está en juego; es decir, la pregunta por la identidad.

Identidad se dice pues de muchas maneras; es un concepto caleidoscópico. Me parece interesante enfocar una característica particular de la identidad latinoamericana en lo picaresco, es decir, en la marca española. Propongo entonces indagar por el carácter fasto y nefasto que constituye, en la antropología filosófico-literaria del hombre americano, la herencia picaresca de corte castellano, mutada en viveza criolla de perfil hispanoamericano. La picardía es sin duda una muestra de cierto tipo de inteligencia; algo propio al hombre como tal. Viva donde viva, y justamente para poder, no tanto vivir, sino sobrevivir. Lo cual requiere astucia y buena picardía. Sin embargo, la intuición que manejo es que la picardía emerge en lo periférico, en lo marginal, allí donde se aísla y refugia una cierta parte de opresión. Lo veremos más 
adelante en el Lazarillo, que no viene propiamente de la fina flor de la Corte ni del Pulpito, sino que los cuestiona y critica bajo capa.

El mestizo latinoamericano es el resultado de una identidad caleidoscopio, compleja y multipolar, en donde se dan cita el conquistador español, el indígena americano, el negro africano y el criollo meridional. Se trata de un círculo tanto virtuoso y tanto vicioso de sincretismo (como en la pintura cusqueña), enajenación y liberación (como en la "Teología de la Liberación"), de metamorfosis y tras tocamientos de universales posibles y mundos diversos y entramados (como en Borges y en García Márquez). Además, a partir de finales del siglo XIX encontramos herencia asiática en América latina (chinos y japoneses en el Perú y en Brasil sobre todo), pero también del oriente mediterráneo, al desplomarse el imperio otomano y durante la Primera y Segunda Guerra mundial: turcos, sirios y libaneses en la costa caribe colombiana.

Me interesa el relato hispano que hace de la picardía un género literario en donde se retrata a una sociedad, pero más interesante me parece ver al pícaro matizado en viveza criolla cuando se positiva, y en malicia indígena cuando se negativa, en las narraciones de la construcción de la identidad latinoamericana. La incursión cruzada por lo picaresco, la malicia y la viveza, es decir por el conquistador, el indio y el criollo, nos llevará a una revalorización del mestizo, entendido como el individuo hoy propiamente latinoamericano. La hipótesis conlleva un tras-tocamiento de identidades diversas. Se busca proponer que el mestizaje sea una potencia antropológica mundial, de orden latinoamericano, mediante la cual se pueda explicitar la dimensión incluyente y el pensamiento complejo, lo distinto, lo opuesto y lo complementario para el buen vivir en sociedades abiertas y democráticas. En un mundo globalizado y globalizador, dicho mestizaje es una fuente inagotable de recurso humano, de energía renovable y renovante, es una fuente de diversidad cultural, ecológica, geográfica, étnica. El mestizaje en América Latina es 
una unidad vital en la diversidad social, natural e individual. El mestizo latinoamericano es un entramado de complejidad.

La hipótesis de trabajo, preciso, es que lo picaresco nos favorece entender el mestizaje y, por ende, la identidad latinoamericana. Porque, en la cuestión de la herencia picaresca de corte castellano, que veremos luego mutada en viveza criolla, hay un problema central de linaje, es decir de reconocimiento.

La fuente convocada para interrogar lo picaresco es un libro clásico en la literatura española. Se trata de El Lazarillo de Tormes, a secas; es decir, La vida del Lazarillo de Tormes y de sus fortunas y adversidades (1940), libro publicado a mediados del siglo XVI en Burgos, Alcalá y Amberes. Como toda gran obra, hay debate sobre su origen y su autor es anónimo; es decir, todos y nadie, como Las mil y una noches, como los "cantos homéricos". Se cree que la edición de Burgos, que fija en 1554 el texto definitivo, es el resultado de muchas copias y de toda una rica tradición lazarillezca. Gregorio Marañón considera que la novela picaresca ha dado de España la imagen de una pícara, y que la historia de España -lo cito- "de la España eterna, se ha de continuar sobre valores de ética rigurosa". Marañón no nos precisa cuales son esos valores de ética rigurosa (sobre todo en pleno franquismo), pero podemos suponer que en esos valores no estaría lo picaresco, ni la astucia, ni la travesura en su tono negativo, es decir vista desde lo vil y lo bellaco, para lo cual propone Marañón que se escarbe valientemente en la conciencia tradicional y se arranque la buena hierba de la picaresca; es decir, el espíritu de lazarillo. En otras palabras, cierta herencia ibérica en donde se encuentra también la América ibérica. Digamos pues, hay que trillar lo picaresco y sacar la paja del trigo, o despulpar y sacar la pulpa, en palabras de cafetero.

La herencia picaresca en América es el conquistador español, tanto el conquistador de tierras y pueblos como el conquistador o 
evangelizador de almas. Tengo para mí, con Enrique Serrano (1997) y su gran ensayo "La Marca de España", que el pueblo castellano -cito"se dedicó ardientemente a la obra de no tolerar la diferencia". El pueblo castellano se dedicó ardientemente, y diría yo, con cruz y con espada, a la obra de no tolerar la diferencia, es decir, a no tolerar la enorme herencia mora y judía. Transportó a Las Indias ese choque de culturas, que había hecho, sin embargo, la riqueza cultural de la Península Ibérica, de la "España eterna". Tenía que recuperar el sur de España, ir de caza por los moros, y entre tanto también iban pagando malentendidos los judíos.

La realeza católica de Castilla \& Aragón apoya la empresa de Colón con un puñado de maravedís y una carabela que se hallaba decomisada por una deuda y que llevará el nombre de la Virgen "Santa María", pero su preocupación central en aquella época era asentar una monarquía católica en guerra con los moros por el sur y con los protestantes por el norte de su inmenso imperio. Un estudio de contabilidad analítica podría concluir en que las Colonias de Indias no le costaron al imperio español sino dolores de cabeza. Es bien sabido que la Corona acordaba generosamente privilegios y no dinero (en el Lazarillo se ve como se hace negocio con indulgencias y bulas). Quien se fuera de colono al Nuevo Mundo tenía que financiar su propia expedición; conquistaba y colonizaba en nombre y bajo derecho real, pero no con dinero de la realeza. Por lo demás, es muy curioso que uno de los más importantes encuentros interculturales de la humanidad, el "descubrimiento de América", acontezca en una época en que la alianza católica, apostólica y romana de las casas Castilla $\varepsilon$ Aragón acaba con el extraordinario aporte de la diversidad cultural que traía la convivencia desde siglos de pueblos de origen, raza y religión diferentes. Es la época de La Inquisición y del exterminio y exilio de judíos en España... muchos se fueron a vivir, conversos, a América.

La herencia picaresca en América es el conquistador español desterrado que se creoliza y busca el reconocimiento de linaje, con lo 
cual aparece el "criollo". Del portugués "crioulo" -criar, "criollo" es un término que surgió en la Época Colonial para nombrar a las personas nacidas en América que descendían exclusivamente de padres españoles o de origen español. También se conocía como criollos a los negros nacidos en el territorio americano. El término, en este caso, se utilizaba para diferenciar a americanos emancipados de raza negra de aquellos que habían llegado desde África como esclavos. La noción de criollo en la actualidad permite referirse a las personas nacidas en un país hispanoamericano, pero también para diferenciar personas, objetos, arte, gastronomía y hasta... caballos. El caballo "criollo" es una raza equina que se cría en América del sur y que desciende del caballo andaluz traído por los conquistadores españoles. "Criollo" es algo distintivo, propiamente latinoamericano. Podemos ver ejemplos concretos de uso moderno regional o local del vocablo "criollo", tal y como lo vulgariza hoy wikipedia.org. En México, el criollo es generalmente de origen español. Sin embrago, todo lo "criollo" está ligado con la identidad del mexicano actual: el idioma, la religión, la cultura, la política, la gastronomía. Las principales representaciones del carácter folclórico mexicano son de origen criollo: el mariachi, el tequila, la charrería, la tortilla de maíz y el chile picante. En Venezuela se considera criollo lo autóctono, independiente de su naturaleza, para diferenciarlo de lo gringo o extranjero. Todo es criollo en Venezuela: comida, vestido, fauna o flora local, habitantes oriundos del país, son criollos. Se considera que un $70 \%$ de los venezolanos se piensan a sí mismos como criollos; es decir, con un componente europeo-español, aunque también lo tengan de mezcla africana, afroamericana o amerindia. En habla vernácula se considera en Colombia que el término criollo evoca idílicamente "la tierra nuestra"; así, se cree, desaparecen las razas y una sola debe llevarse con orgullo: la criolla.

Así pues, es como si todo el legado nativo y africano, y ahora de oriente medio, se fundiese en lo colonial y criollo. O criollo también se vuelve gallina criolla, que es más pequeña y contiene más sabor -una 
manera de ser local y chovinista; se degusta al preparar el sancocho de gallina- el que se trata de "criolla" se sobreentiende- que en Argentina llaman sopa criolla, con lo cual lo criollo da linaje y selectividad a la gallina, como en regiones de los Andes al caballo. Es decir que, del gran sujeto criollo que piensa la narración de la independencia, un Simón Bolívar, pasamos al caballo criollo o a la gallina criolla (paso interesante de lo sustantivo a lo adjetivo, con lo cual concluiré más tarde mi conferencia).

\section{Volvamos a lo Picaresco}

Lazarillo es y sigue siendo un libro absolutamente moderno. "De novedad absoluta", lo calificó uno de sus mejores conocedores, el francés Marcel Bataillon. El libro aparece en pleno Siglo de Oro Español, que es la época clásica o de apogeo de la cultura y del Imperio Español, siglo que está marcado por el posicionamiento de España como potencia ultramarina, fuerte extensión y colonización en América. Siglo de Oro que ve armar la famosa, grande y felicísima armada, conocida comúnmente como Armada Invencible o Armada Española, nombre que dio el Rey Felipe II a la extraordinaria flota que armó en 1588 para invadir "La Pérfida Albión" (Inglaterra); siglo que también ve nacer al Fraile dominico Bartolomé de Las Casas, "el apóstol de los indios". Neira (2010), nos recuerda que en la llamada "Querella de Valladolid", el obispo de Chiapas, la Corona decreta que los indios no sigan siendo materia de esclavitud, pero se busca entonces otras víctimas, como ironiza Borges en su cuento El atroz redentor Lazarus Morell:

En 1517, el padre Bartolomé de las Casas tuvo mucha lastima de los indios que se extenuaban en los laboriosos infiernos de las minas de oro antillanas, y propuso al emperador Carlos V la importación de negros, que se 
extenuaran en los laboriosos infiernos de las minas de oro antillanas.

Néstor García Canclini (1999) denuncia en su Globalización imaginada el "binarismo maniqueo" con que ciertas narraciones de la independencia elaboran la tesis hispanista contra la tesis indigenista: la una adjudica el bien a los colonizadores y la brutalidad a los indios, mientras que, para la tesis indigenista o étnica, los españoles y los portugueses no pueden ser más que destructores. Es ciertamente una oposición simplificadora. El proceso independentista se alimenta de esa oposición, hasta que logra en el concepto de "americano", à través de la acepción "criollo", un camino que todavía está por explorar para llegar al mestizo latinoamericano.

Sobre El lazarillo de Tormes en particular, y la literatura picaresca o lazarillezca, se han escrito miles de libros. El tema es que el librito, de apenas 100 páginas para siete tratados que son como tal un decir, refleja vanidades, contradicciones e injusticias de una sociedad imperial en pleno apogeo cultural y militar. Fortunas y adversidades del lazarillo son como grandezas y decadencias de la sociedad en que vive. Un resumen a la Internet diría simplemente que es la novela de un pícaro que sirve a diversos amos, aprovechándose invariablemente de ellos.

Algunos dirían que es un proceso des-educativo o un proceso educativo. Y no concuerdo con el hecho de que El lazarillo de Tormes sea un proceso des-educativo pues en realidad se trata de un extraordinario proceso de oposiciones, donde aparecen los simulacros de una sociedad y sus representantes principales: curas y nobles, en primera línea, que predican y no aplican.

En El lazarillo aparece la figura de un "don nadie" de un antihéroe, y tiene la apariencia de una autobiografía; sin embargo, el texto es anónimo y se cree que sea el resultado recopilado de anécdotas diversas 
en los barrios pobres de Toledo. Escrita en primera persona y en estilo epistolar, la novela cuenta cómo, de amo en amo, llega un pobre diablo a tener un oficio que le asegura de por sí la existencia sin tener que mendigar o servir a otro amo. Lo de epistolar es por lo de moralizante. Género literario para cuestiones éticas, la carta o epístola servía de manual ético desde los griegos y romanos, pasando por las epístolas de los Apóstoles.

En el apogeo de un imperio ultramarino, prescriptor de artes y leyes, en donde todavía la literatura pagana aceptada por La Inquisición o mal llamado "Santo Oficio" católico, apostólico y romano eran los relatos de caballerías y la novela del amor cortés: angélicos, pastores y plebeyos enamorándose de princesas y otras damas de alto rango en la corte, he ahí que aparece una cuartilla anónima de apenas 100 páginas que trastoca cualquier molde o género literario, por lo que surge un nuevo género: el picaresco.

Se trata de un librito o manual de aprendizaje de la vida. La novela picaresca es el subgénero literario específico del realismo de cierta miseria material, dirán unos, espiritual dirán otros. Mediante el recurso de la parodia de narraciones caballerescas que idealizanel Renacimiento Español, a las rimbombantes epopeyas de gestas guerreras y libros de amor cortés se opone una epopeya del hambre y la miseria, que mira solamente a cuanto hay por debajo del cuello de golilla y se preocupa solamente de la subsistencia. Recordemos que, a finales del siglo XIX, el Martín Fierro es también una epopeya del hambre, de la miseria del gaucho.

La temática de El lazarillo es moral, una crítica en parodia, pero acerba; incluso una denuncia en filigrana del falso sentido del honor, la negra que llaman honra, y de la hipocresía. La dignidad humana sale muy mal parada de la sombría visión que ofrece el texto nihilista y anticlerical, pero terriblemente realista cuando se piensa en las 
condiciones de subsistencia de un pobre en cualquier tugurio de los suburbios de cualquier ciudad del mundo.

La vida es dura y, tal como aconseja el ciego a Lázaro en la obra -cito: "más da el duro que el desnudo", cada cual busca su aprovechamiento sin pensar en los demás, por lo que, como se dice al principio de la obra, "arrimándose a los buenos se será uno de ellos". Esto lo cuestionaremos. ¿De qué bueno se trata? Aunque el proverbio popular sea: "a quien a buen árbol se arrima, buena sombra lo cobija", se puede ver aquí la virtud de la imitación o un simulacro de la hipocresía: que para ser virtuoso haya que fingir serlo, no siéndolo. Podemos ver la visión de un humanista desencantado, pero también un pintor de la condición humana, acaso judeo-converso y hasta inspirado por los humanistas renacentistas, entre los cuales puede contarse Erasmo.

La novela picaresca parodia un sistema y lo critica con lo absurdo de situaciones y contradicciones. Dos instituciones salen muy mal paradas: la iglesia y la aristocracia, responsables de una sociedad hipócrita en donde reinan el simulacro y el hambre.

La edición de Víctor García de la Concha en la Biblioteca Austral publicada en Madrid en 1940, nos presenta una lectura de El lazarillo siguiendo la ley de tres -propia de la narrativa folclórica-, con la repetición de tres módulos ternarios. He aquí su esquema: prólogo, proemio, preámbulo. Una apertura: los orígenes del antihéroe, las dificultades familiares y la emigración del hogar. Luego, el aprendizaje de vida o carrera de vivir con amos y/o maestros igualmente es un módulo ternario: primer amo (un ciego, un clérigo, un escudero); primer módulo. Segundo modulo ternario: segundo amo (un mercedario, un buldero, un maestro pintor). Y termina el último módulo: tercer amo (un aguador, un porquerón de alguacil y un pregonero). El cierre es igualmente un módulo ternario: matrimonio y asentamiento, dificultades familiares (malas lenguas, rumores, una historia de infidelidad) y la superación 
de este infortunio, el estado de fortuna y la lección final o regreso a la lección materna.

El uso de estructura anular y terciaria hace de la novela un juego literario en polifonía, donde el personaje principal cambia y evoluciona pasando de la ingenuidad fruto de la ignorancia a cierto cinismo; es como si, del saber que da la experiencia de vida, al final uno aprendiera a vivir con lo que le toca. No es resignación sino sabiduría popular. Lo vemos en el caso complicado que cierra el libro, el de la supuesta infidelidad de la mujer de Lázaro.

Uno de los curas de la Parroquia de Toledo, a la que pertenecían familias nobles, procuró cazar al lazarillo con una de sus criadas; -cito-: "viendo mi habilidad y buen vivir, teniendo noticia de mi persona, el Señor Arcipreste de San Salvador, mi señor, y servidor y amigo de vuestra merced, porque le pregonaba sus vinos procuró casarme con una criada suya". Matrimonio pragmático, por conveniencia e interés, no por sentimientos. Esto no se dice; la gente pobre del pueblo raso no anda con sutilezas de amoríos y el discurso del amor cortés ya, para Lázaro de Tormes, no está de moda.

Así mismo, se trata de la aceptación final que de un cura solo puede venir lo mejor, o se espera que de un cura venga lo mejor, pero no tanto en lo espiritual, en este caso, sino en lo material. O, digamos, que ya no es el problema. Escuchamos la justificación del matrimonio según Lázaro, -cito-:

y visto por mí que de tal persona -el cura-, no podía venir sino bien y favor, acordé de lo hacer -el matrimonio- y así me casé con ella y hasta ahora no estoy arrepentido porque, allende de ser buena hija, y diligente servicial -la criada-, tengo en mi Señor y Arcipreste todo favor y ayuda. 
Como El lazarillo es la parodia social de una hambruna cotidiana, es normal que favor y ayuda tengan que ver con el comer pues el meollo del vivir es aquí la subsistencia, no tanto de pan divino sino terrenal, porque el cura siempre en el año, le da -se supone que a la dicha mujercerca de una carga de trigo y carne por las Pascuas. En fin, precisa Lázaro,

los domingos y fiestas casi todas las comíamos en su casa.

Pero el rumor de las malas lenguas, que nunca faltaron ni faltarán, no nos dejan vivir diciendo no sé qué y sí sé qué, de que ven a mi mujer irle a hacer la cama, y guisarle de comer, y mejor les ayude Dios que ellos dicen la verdad.

Ya asentado, reconocido en sociedad y con trabajo honrado de pregonero -aunque lo de pregonero está por analizar también-; De La Concha recuerda hábilmente que el pregonero puede ser a su vez un pícaro, pues tenían los pregoneros fama de dar gato por liebre, con lo que el manual de vida o carta epistolar de El lazarillo llevaría igual cierto simulacro individual del simulacro general en la sociedad española del Siglo de Oro. Pero también, el oficio de pregonero tenía en aquel entonces cierto reconocimiento, pues hay en pregonar un derecho tradicional y otorgado por gritar en público el anuncio de orden religioso -una misa por decir- o de justicia. Publicidad, diríamos hoy. Lázaro está pues entre el pregonero de mercancías -los vinos del cura- y pregonero del alguacil.

El Tratado Séptimo precisa: "asenté por hombre de justicia con un alguacil, más muy poco viví con él por parecerme oficio peligroso. Mayormente, que una noche nos corrieron a mí y a mi amo a pedradas y a palos unos retraídos" (delincuentes asilados en una iglesia donde no podía entrar la justicia por clara separación de poderes entre lo espiritual y lo terrenal). Con lo cual y finalmente, Lázaro termina asentándose en el oficio de pregonero. Insiste la crítica en la vileza del oficio, confiado al parecer en aquella época a moriscos. De La Concha precisa que 
consistía, sin embargo, en discreta fuente de ingresos y que, clasificados en pregoneros mayores y menores, a aquellos -entre los que parece estar Lázaro- se les exige honestidad de vida, aval de señores notables y un depósito pecuniario de fianza.

Manejando el texto en tríada, donde aparece e interactúa el tercio excluido, este, digamos, manual de vida del hombre moderno en el Siglo de Oro Español muestra un trabajo en tres dimensiones diferentes, integrando al comerciante publicista en vinos, al usurero o ilusionista, pregonero en "almonedas (objetos prendados o prenderías) y cosas perdidas" -casi que uno podría pensar en un pregonero de causas perdidas$y$, tercero, al que acompaña a los que padecen persecuciones por justicia y declara a voces sus delitos: "pregonero, hablando en buen romance," precisa Lázaro de Tormes. Con esta tercera dimensión en la vida laboral y final compensado de Lázaro, siento cierta y dolorosa emoción. Lázaro, o el paradigma picaresco, es la herencia del conquistador español que heredará el criollo, que no es -hemos dicho- ni español ni indio, solo un americano mediano; es decir, algo entre dos aguas o entredicho.

Lázaro termina como pregonero de aquellos que sufren, que padecen persecuciones por justicia, como el padre del mismo Lazarillo. Recordemos el Tratado Primero en donde Lázaro presenta su familia, pero antes... el prólogo del texto introduce el tema del linaje, hilo secreto de todo el debate: la cuestión de la identidad y del reconocimiento, pero también el tema álgido de la herencia por sangre o derecho natural, o por cultura o derecho adquirido; es decir, por educación y aprendizaje.

El anónimo autor presupone de entrada que, citando a Plinio El Joven (Epístola III, V-10), "no hay libro, por malo que sea, que no tenga alguna cosa buena". El libro es trabajo de artistas, como la guerra de soldados, y tanto el uno como el otro, dice Lázaro en el prólogo, pone en peligro. Se espera, en filigrana, que en el combate la espada del guerrero no sea de palo, como para el pregonero de vida -en el caso del 
sermón de cura o del Manual de Aprendizaje-, haya algo de verdad en la promesa del sermón, haya algo de verdad en la propuesta de manera de conducir su vida. Que el cielo exista y que el comportamiento ético tenga sentido.

Lázaro pide solamente que de lo que va a contar, en "grosero estilo" -se justifica-, para de entrada ponerse fuera de la crítica literaria académica, se saque algún gusto -el relato comienza al salir de Salamanca, es decir, fuera de la reputada universidad. Digamos también que no tiene, pues, más pretensión que lo estético, a diferencia de una epístola moral clásica donde, por supuesto, no es lo estético sino lo ético, la cuestión moral, lo que va a estar en juego. De entrada, El lazarillo de Tormes dice: "de lo que les voy a contar de mis fortunas y adversidades espero que saquen por lo menos algún gusto". Y ahí, va contra el tradicional manual moral y ético. La novela picaresca dará cuenta de la moral pervertida y de la necesidad de un comportamiento ético. Por cierto, se podría leer El lazarillo de Tormes como un juego estético y no como un tratado de moral; sin embargo, tengo para mí que El lazarillo es una cuartilla de educación para mostrar, contra los que dicen en la corte que "lo que natura no da, Salamanca no lo presta", que la educación, en este caso "la universidad de la vida", sí presta y enseña lo necesario para medrar, es decir, progresar, y no solo en el sentido crítico, subyacente en la filigrana de la conclusión sobre su estado laboral y reconocimiento de buena vida final cuando Lázaro dice -cito-: "y con favor que tuve de amigos y señores, todos mis trabajos y fatigas hasta entonces pasadas fueron pagadas con alcanzar lo que procuré, que fue un oficio real"; entiéndase socialmente reconocido y buen pago, entiéndase también concreto, en donde se gane algo... "viendo que no hay nadie que medre-que progresesino los que detienen el oficio real".

El autor reconoce que para alcanzar un "oficio real" hay dos caminos; lo precisa en el prólogo. Es el mensaje subliminal de entrada. Trabajos y fatigas por Lázaro vividas lo son por todos los pobres diablos 
que sin herencia otra que la picardía -arte de sacar enseñanza del simulacro- llegan a algo en la vida. Que fortunas y adversidades de El lazarillo sirvan pues, no únicamente para que "se tenga noticia de mi persona" -esto es menor y hasta chistoso pues el libro es anónimosino ante todo que consideren los que heredaron nobles estados cuán poco se les debe, pues fortuna fue con ellos parcial, y cuánto más hicieron los que, siéndoles contraria, con fuerza y maña remando salieron a buen puerto". Esta me parece ser la razón final del texto, el porqué de justificación de fondo para los que no tienen linaje de sangre, sino de educación, para verdaderos cristianos y no vanidosos católicos. Así pues, "a Dios rogando y con el mazo dando".

Uno entiende aquí por qué en la cultura, en educarse y cultivarse hay un peligro de revolución; uno entiende también la razón de fondo de toda Teología de la Liberación para sacar los pobres con educación de la ignorancia y la pobreza, es decir con ilustración; uno entiende por qué El lazarillo de Tormes, y con él todos los lazarillos, sufren y sufrieron La Inquisición. Con esto queda dicho también que ningún noble, monarca o conquistador puede encaramarse en derechos esenciales de corte pontifical y/o divino; que consideren los que heredan -por tener derecho natural o divino, que consideren los nobles, es decir, por sangre o linaje-cuán poco se les debe.

Uno entiende mejor por qué, casi tres siglos después, el textico de El lazarillo seguiría siendo una bomba cultural, revolucionaria, trastocando en parodias picarescas los estatutos establecidos con la arbitrariedad de "derecho real" o "divino." Entiende uno mejor el fervor contradictorio del criollo genial y paradigma del hombre de la independencia, Simón Bolívar, al escribir la "Carta de Jamaica" tres años después de que el fraile revolucionario chileno Camilo Enríquez escribiera este cuarteto, cito: "¿Hasta cuándo en papeles miserables / se buscan los derechos? La suprema / mano los escribió en los corazones: / esta es la voz de la naturaleza". El mensaje impresionante en juego, y del cual 
son responsables los filósofos ingleses y alemanes del "derecho natural", pero igualmente todo el proceso europeo de ilustración y de revolución copernicana de la mente moderna, es el desligamiento del "derecho natural" de toda fuente divina. Tal derecho es la voz de la naturaleza en los corazones de los hombres y no la voz de Dios, con lo cual -como diría Scavino,

la cesión papal de los territorios americanos a los monarcas españoles carece entonces de legitimidad desde la perspectiva del derecho natural. Y como la libertad es un derecho natural, los americanos no deben sentirse obligados por aquellos documentos (reales): la revolución de la independencia de España puede iniciarse pues, teopolíticamente justificada.

El contexto europeo juega también, desde el advenimiento del protestantismo o la ilustración a través de la lectura y la interpretación de la simple razón hasta Napoleón y la caída de los Borbones y el surgimiento de la autonomía de las Cortes, pasando por la Revolución francesa.

El problema es que nunca basta con liberarse de la esclavitud de un régimen o de una ideología o de alguna obsesión mental o vicio umbilical; se requiere liberar de servidumbres no solo el corazón sino la mente (siendo la "servidumbre voluntaria" la más difícil, como lo precisa De la Boetie). Se requiere educación. Recordemos al Libertador en su discurso inaugural del Congreso de Angostura, 15 de febrero de 1819; cito: "nuestras manos ya están libres y todavía nuestros corazones padecen de las dolencias de la servidumbre." Bolívar sabe que, para no seguir "arando la mar", se requiere más que una revolución política y militar; se necesita una revolución educativa, mental y paradigmática; y no es con guerra y armas que se obtiene. Recordemos la famosa frase que sostiene, desde el frontispicio, los pilares del palacio constitucional 
colombiano; cito: "Colombianos, las armas os han dado la independencia, las leyes os darán la libertad." Francisco de Paula Santander. Es un futuro de confianza.

Si El lazarillo, o lo picaresco, es la herencia hispana, una de las marcas de España en el criollo y por ende en el mestizo latinoamericano, veamos el linaje del Lázaro de Tormes. Huelga de entrada decir que este "De" posesivo y señorial, a la manera de nobles -"De Tormes"-, está de más en el miserable y plebeyo hijo de Tomé González y de Antona Pérez, naturales de Tejares, aldea de Salamanca. En realidad, el nombre "de Tormes" es un apodo o sobrenombre porque nació en ese río homónimo y no porque tenga linaje noble. Lázaro González Pérez cambiará de nombre al final de su recorrido de vida y se convertirá en Lázaro de Tormes, a secas. Así ocurría con muchos de los colonos españoles de baja alcurnia y dudoso linaje cuando llegaban a tierra americana en busca de hidalguía imaginada. Se juega a las epístolas, a enviar cartas para buscar opinión favorable, se acostumbra fingir correspondencia donde "grandes" traten a "menores" de "caballero", y se hace mención de supuestas hazañas. La sabiduría popular dice que "miente de veras el que viene de lejos." De igual manera que pregona vinos, Lázaro propone en su relato pregonar vivencias para dar testimonio de honra y linaje adquiridos por experiencia... "con fortuna y maña remando, salir a buen puerto".

Cuando Lazarillo tenía apenas 8 años, a su padre achacan ciertas sangrías mal hechas y lo destierran quedando con reputación de ladrón; padeció persecución por justicia, dice Lázaro en el Tratado Primero. Desterrado, lo enrolan en cierta "armada contra moros"; o sea que, enrolar como carne de cañón... "no hay nada nuevo bajo el sol." Desterrado, decía, se puede suponer la ambigüedad del texto y que se pueda entender, en filigrana, un linaje converso en sangre lazarilla y/o criolla. 
La búsqueda de linaje perdido es tan necesaria que el pícaro por antonomasia, Lázaro, se convierte en un "hideputa". El texto no es claro: viuda o separada, la madre de Lázaro, "sin marido y sin abrigo, vinose a vivir a la ciudad, frecuenta caballerizas y se vino en conocimiento, amancebamiento y trato ilícito con un hombre 'moreno' -precisa el texto- de aquellos que las bestias curaba". El autor escribe "políticamente correcto" hablando Lázaro de su padrastro. Según el diccionario de autoridades, solía llamarse "hombre moreno" al negro atesado; moreno pues, y por suavizar la voz, negro. Del amancebamiento nació "un negrito muy bonito, el cual yo brincaba y ayudaba a calentar" -cuenta Lázaro. Sigue una escena dolorosa en donde la madre de Lázaro es tratada de puta, el niñito de hideputa, es decir el hermano medio de Lázaro, siendo éste entonces el hijo de una madre puteada. Una blanca y un negro no podían amancebarse. El negro, natural de Mozambique, robaba para poder dar de comer a su amante y su crío. Al delito de robo se suma la circunstancia agravante, según la cual, se consideraba la cohabitación de una mujer con hombre de otra ley como incesto y hasta herejía. Había en aquella España del Siglo de Oro un manual de castigos y preveía 100 azotes para el esclavo negro, 100 azotes para la sirvienta blanca; se prohibió a los amantes ilícitos que se volvieran a ver y la justificación que Lázaro da al hurto de su padrastro para mantener a su mamá y a su hermanito medio es la siguiente: robaba por amor, y lo compara con curas que desfalcan las limosnas para ayudar a sus amantes a cuidar sus hijos. Escuchemos el argumento, que es bien sentido: "no nos maravillemos de un clérigo ni de un fraile, porque el uno hurta de los pobres y el otro de casa para sus devotas y para ayuda de otro tanto -entiéndase, ayudar amantes a cuidar hijos de ellos-, cuando a un pobre esclavo el amor le animaba a esto". La pobre mujer se muda con sus dos hijos a un mesón. Allí llega el famoso ciego, quien será el primer "amo maestro" de Lázaro. El ciego pide a Antona Pérez que le confíe el mozuelo; ella lo hace, rogando que lo trate bien y mirase por él, pues era huérfano. 


\section{Contra la Hambruna del Vientre y del Espíritu}

Lázaro se exilia y se afinca en Salamanca, pero es un exiliado del interior en la ciudad del saber por excelencia, en época del Siglo de Oro español, y allí debuta su carrera de vida, su trabajo de lazarillo, con un ciego. La escena de adiós, pues nunca más volverá a ver a su madre, es muy emocionante. Veámosla: "(...) y cuando nos hubimos de partir, yo fui a ver a mi madre y, ambos llorando, me dio su bendición y dijo: 'hijo, ya sé que no te veré más; procura de ser bueno y Dios te guie. Criado te he y con buen amo te he puesto; válete por ti'". La herencia que Lázaro recibe de su madre no es oro, es un consejo, es una sentencia: "válete por ti" es la más importante de las sentencias educativas de toda la historia de occidente. Traduzcámosla a su origen griego: "conócete a ti mismo". Se trata de una advertencia inscrita en el frontón de entrada del templo dedicado al Dios Apolo, en Delfos, en la Grecia Antigua. Se refería al cuidado que el humano debía tener con lo desmesurada o falta de cordura, en relación al poder divino. El padre de la filosofía occidental, Sócrates, transforma dicha advertencia en piedra angular del filosofar tradicional.

La crítica ha señalado como vector semántico principal de los Tratados Primero, Segundo y Tercero la temática del hambre, y en esto El lazarillo de Tormes es de una modernidad extraordinaria porque, si hay algo todavía en el Bicentenario, en la suerte futura y en los proyectos concretos y verdaderos por construir en los estados-nación que están celebrando el Bicentenario, es el tema del hambre.

Lázaro busca valerse por sí mismo con los tres primeros amos que encuentra: un ciego, un clérigo, un escudero. Se trata de un aprendizaje por medio de la picardía, a través de la picardía: la astucia del ciego, la mezquindad y avaricia del clérigo y la vanidosa apariencia del escudero. El ciego enseña a Lázaro a ayudar a dar misa; enseña lo que no sabe y lo que no es. Podríamos decir que el ciego enseña lo que no ve, pero con eso facilita sin embargo la entrada de Lázaro al servicio del clérigo 
que será su segundo amo. El cura solo comía para él, pero predicaba al pobre mozo ocultando la mezquindad con palabras sabias; cito:

mira, mozo, los sacerdotes han de ser muy templados en su comer y beber, y por esto yo no me desmando como otros, más el lacerado mentía falsamente, porque en cofradías y mortuorios que rezamos, a costa ajena comía como lobo y bebía más que un saludador, es decir, gente sin escrúpulo.

En esta pintura el Lazarillo da clara cuenta del comportamiento de ciertos curas, esos mismos que seguían la tradición de los bizantinos tradicionales que echaron a perder el imperio romano de oriente. Si Lázaro no dejaba al clérigo era por dos cosas: porque la flaqueza de las piernas le impedía casi moverse y porque uno nunca sabe... "salir de Guatemala y caer en Guatepeor", o, como dice el texto, "escapado del trueno para dar en el relámpago." Eran sentencias corrientes de la sabiduría popular. La generosidad del clérigo para con Lázaro es una falsa magnanimidad que acentúa la parodia. Como los sábados comía el cura cabeza de ternero, pues la cocía y comía los ojos y la lengua y el cogote y sesos, y la carne con las quijadas, daba todos los huesos roídos al pobre Lázaro en el plato vacío, pero le daba un aprendizaje satírico. Pasamos en la filigrana del alimento terrestre al educativo o espiritual: "toma, come, triunfa, que para ti es el mundo; mejor vida tienes que el Papa". Tener "mejor vida" por no tener nada que cuidar o proteger y por eso mismo, en tradición estoica, no cargar penas ni preocupaciones.

Volviendo al tema en El lazarillo, a la temática educativa formal pero también a la temática informal, resulta jocoso constatar que el aprendizaje de vida o la educación propiamente dicha, que empieza con los dos amos, primero con el ciego o la ceguera, el despertar de la ignorancia, le va a nuestro mozuelo después de haber sido criado por su madre... "criado te he y con amo te he puesto". Pero "ivaya por bueno!, un ciego". Afortunadamente la última y valiosa recomendación de la madre 
es "válete por ti", como si se nos recordara que con ese empujoncito sacáramos del nido a los pichones para que levanten vuelo: que se valgan por sí mismos.

"Salíamos de Salamanca", cuenta Lázaro, y es una ironía o picardía deliciosa pues residía en Salamanca la más importante escuela, liceo o universidad de la historia de España. Era tan famosa que corría el dicho - ya lo he recordado - que "lo que natura no da, Salamanca no lo presta". Y vemos, sin embargo, que la educación o el aprendizaje por maña, astucia y picardía empieza al salir de Salamanca. Y es así para el pobre Lázaro porque no hace parte de la élite, de los ricos que tienen con qué y pueden ir a la universidad. La universidad de Lázaro va a ser la calle y el poder ver y descifrar las apariencias del mundo y las personas, de los valores dominantes y de los dogmas católicos, aprendizaje con simulacros.

Lázaro considera útil en el prólogo contar sus fortunas y adversidades, casi que en tono sociológico y político, amén de estético y divertido lo dije antes: "consideren, los que heredaron nobles estados, cuán poco se les debe pues fortuna fue con ellos parcial, y cuánto más hicieron los que, siéndoles contraria, con fuerza y maña remando salieron a buen puerto". $\mathrm{Y}$ eso es un buen consejo para los que han venido a ésta cátedra por créditos, igualmente: con fuerza y maña, remando, salir a buen puerto.

Saliendo de Salamanca, recibe el lazarillo su primera lección. Tendrá por resultado, y lo dirá el mismo Lázaro, "despertar de la simpleza en que, como niño, dormido estaba"; y precisa que ese salir del sueño de la infancia, que también se entiende de la ignorancia, y acceder a edad de razón, es para avivar el ojo y avisar, "pues solo soy, y pensar cómo me sepa valer". Veamos la lección que es bien pintada y parece una miniatura de esas que publicaban los jesuitas para educar-evangelizar a los indígenas. 
Salíamos de Salamanca y llegando al puente está a la entrada de ella un animal de piedra que casi tiene forma de toro y el ciego mandóme que llegase cerca del animal, y allí puesto me dijo: 'Lázaro, llega el oído a este toro y oirás gran ruido de él' -un toro de piedra. Yo simplemente llegué, creyendo ser así, y como sintió -que es otra manera de verque tenía la cabeza par de la piedra, afirmó recio la mano y diome una gran calabazada en el diablo del toro, que más de tres días me duró el dolor de cornada, y díjome: "necio, aprendé, que el mozo del ciego un punto ha de saber más que el diablo', y rió mucho la burla. Parecióme que en aquel instante desperté de la simpleza.

El texto contiene una serie de sintagmas relativos al saber, ligado éste a la tradición judeocristiana del Siglo de Oro Español, al diablo y, en la figura del toro, a la idolatría; toro o becerro de oro, en definitiva animal idolatrado. La tradición bíblica asimila igualmente la figura del diablo o demonio al saber de aquel ángel desterrado de los círculos divinos por querer y buscar saber más que Dios.

El juego de palabras, en simetría con respecto al saber y la ignorancia y a sus respectivos protagonistas -el aprendiz: Lázaro, vidente, y el amo: maestro ciego-, sigue enseguida en la segunda lección y reza: "comenzamos nuestro camino" - camino del conocimiento, preciso; recordemos que método es también camino. Comenzamos nuestro método "(...) y en pocos días me mostró jerigonza" - una jerga de germanía y maleantes, el dialecto de los extraños, foráneos y fuera del orden y la ley; el dialecto de los bárbaros... los que no tienen la palabra oficial, por decirlo así- y como medio de buen ingenio -es decir, aptitud al aprendizaje-, holgase mucho y decía: -segunda lección: "yo oro ni plata no te lo puedo dar, mas avisos para oír muchos te daré". Huelga recordar la tradicional sentencia bíblica al respecto del valor del saber, de lo que vale en dinero pero que se cuenta con otra moneda que con oro y con 
otro canon que el tradicional: "no solo de pan vive el hombre". Somos o no somos aventaderos de mundos posibles. Sentencia difícil a manejar en una teología tradicional de ricos y burguesía, como igual lo es, y hasta injuriosa, en una teología de la liberación del hambre y de la miseria social. Lázaro saca la siguiente conclusión: "y fue así que, después de Dios, éste me dio la vida y siendo ciego me alumbró y adiestró en la carrera de vivir". Es a la luz del saber que el ciego conduce y en lo cual adiestra al, sin embargo, vidente y, como lazarillo, encargado de conducir al ciego por buen camino.

Lázaro, o el anónimo autor, es consciente que está contando anécdotas poco profundas en apariencia y se excusa en la carta dirigida -recordemos que el texto es una misiva en donde se cuenta "a vuestra merced", es decir a alguien superior en jerarquía social como se logra salir adelante en la vida y frente a la adversidad: "y a lo que dice vuestra merced; huelgo de contar a vuestra merced éstas niñerías, para mostrar cuanta virtud sea saber los hombres subir siendo bajos y dejarse bajar siendo altos, cuanto vicio".

Está claro que las lecciones de El lazarillo, así lo sean en parodia, son de alto vuelo y, aunque contadas por plebeyos, son de alta alcurnia pues el tema de la educación es, era y será el tema del combate interactivo y complejo entre el vicio y la virtud.

He venido trillando o despulpando la noción de picardía porque tengo para mí que, mutada en viveza criolla de corte paisa, hay algo más que una patente de corso a la acción baja y vil, a la bellaquería, en las picardías o travesuras que caracterizan la viveza criolla. Frente a la cáustica parodia del pícaro hay una casuística por desgranar, ya no como el estudio teológico de los casos de conciencia del criollo sino como fenómeno antropológico de la cultura del atajo, de la trampa, el hurto y el soborno como alternativa a la hambruna y al destierro. 
Lo criollo ha sido idealizado como lo autóctono después de haber sido el apodo despectivo para los oriundos de España nacidos en las Indias, y esa conciencia desgarrada del criollo, consciente de ya no ser de allá -España- y todavía no tener raíces acá -América-, abre el tema moderno de la identidad por venir del mestizo latinoamericano: el nuevo hombre capaz de asumirse a sí mismo, tener dignidad y forjar una gesta legisladora inédita. Siendo una especie media asumida, ni europeo ni aborigen, simplemente paisano, el criollo elabora la narración de la independencia; pero la nueva ciudadanía no es ser criollo ni tampoco americano, lo criollo fue una narración de identidad para inventar al hombre americano meridional en los nuevos derechos, soñando una nueva patria, una madre patria fraterna; soñando América como patria, decía luego Martí, retomando la "Carta de Jamaica" y el Discurso Inaugural del Congreso de Angostura: asumiendo la posta bolivariana.

Sin embargo, la realidad es que el noble sustantivo "criollo" no superó en el nuevo hombre americano su conciencia desgarrada, su fervor contradictorio, y el furor de la historia llevó los pueblos nacientes a ser ciudadanos de Estado sin nación y naciones-pueblos sin otro Estado que una ficción o relato constitucionalista y romántico descontextualizado. Son pues 200 años en búsqueda de un Estado para el ciudadano argentino, chileno, venezolano, colombiano, mexicano; es decir, un Bicentenario tratando de construir ciudadanía y nación para el Estado de Derecho en estas repúblicas. Lo criollo dejó de ser sustantivo para transformarse en adjetivo que conserva la ambigüedad de tener a su vez una connotación virtuosa y viciosa. Ésta se constata particularmente en la famosa viveza criolla que da gracia, incluso risa, pero que también es humor negro cuando vemos el degradante componente antisocial que arrastra ríos fangosos de resentimiento y que, simulacro inteligente porque desvela una fractura y como tal es catarsis, la viveza criolla es también patente de corso a la bellaquería. 
"El vivo" cree ser como "el putas de Aguadas" - para hablar en lenguaje coloquial. Es, pues, un ufanado con pies de barro. Su afán de sobrepasarse no es en solidaridad con su entorno y con los demás; el vivo es un pícaro que obtiene de cada situación "su pedazo de longaniza" en la torta del mundo, como en El lazarillo de Tormes. En su carácter pedagógico, la viveza aparece como una educación popular. Abundan sentencias y consejos sobre el tema, como si la sabiduría popular aceptara que "es mejor - o trae menos perjuicios - "atajar vivos que empujar sonsos".

Es interesante que mientras la viveza criolla en el paisa colombiano, por ejemplo, tiene la connotación positiva de un aventajado en el trabajo, recuperando la herencia picaresca de que "al que madruga Dios le ayuda", en Argentina, por el contrario, dice el escritor Aguinis (2002) en su libro El atroz encanto de ser argentino que la viveza criolla es lo contrario de trabajar, pues madrugar no es levantarse con el sol suave de la mañanita para laborar mejor sino que, en sentido criollo, madrugar es sorprender, golpear primero para sacar provecho de una situación. "El vivo" sabe simular, fingir, poner cara de "eso no fui yo". Hace parte de la herencia picaresca; es decir, se hace el maravillado, el primero en extrañarse porque no parece hallársele razón razonada a algo que ocurre y de lo cual él es responsable, o también, porque pueden dársele razones contradictorias a lo ocurrido. Atrapado con las manos en la masa, "el vivo" es capaz de simular extrañeza simulando simulacro y desdoblamiento. Entre los perfiles nefastos de la viveza criolla encontramos un gozo particular por la transgresión. "El vivo", como tal, es un incrédulo en la justicia. Es herencia picaresca. Podríamos notar que se trata de un acto-transgresión revolucionario porque lo que se dice justo, bueno o bello, no lo es.

La verdad es que "el vivo" no busca la justicia inmanente sino la ventaja personal, por eso no es un Robín Hood que roba a los ricos para dar de comer a los pobres. "El vivo criollo" no cree en la honra 
ni en la honestidad porque considera que son valores burgueses; es decir, los valores establecidos por la clase dominante. Su condición de resentido social lo lleva a despreciar trabajo, honra y virtud, con lo que se diferencia de El lazarillo pues la lección final de Lázaro es "arrimarse con los buenos para ser bueno", respetar el contexto social de la vida en ciudad, derechos y deberes ciudadanos; trabajar y vivir en paz. La aparente inteligencia del "vivo" es en realidad un brillo de corta duración. En esto tiene también herencia picaresca pues lo que le importa es el goce inmediato, la ansiedad del exitista. Recordemos el episodio de la longaniza en El lazarillo: "como me vi con apetito goloso, habiéndome puesto el sabroso olor de la longaniza, del cual solamente sabía que había que gozar no mirando qué me podría suceder, puesto todo el temor por cumplir el deseo" - y no en lo que le va a suceder -.

Sin embargo, tengo para mí que la viveza criolla va un paso más adelante pues no solamente saborea el deseo, sino que se cuida del entorno y maneja una prudencia astuta de sobornos. Es el caso de los refinados refinadores del tráfico de drogas. La viveza criolla, además de ser una vulgar transgresión por su extracto resentido, es también búsqueda refinada y seductora, picaresca.

Estudiosos de la viveza criolla ven en ella la herencia de una cultura encomendera. Recordemos que la encomienda es la institucionalización de "la vacuna" y de "la coima" durante la Colonia. Era la institución colonial española en América basada en el repartimiento de indios entre los conquistadores. El indio debía trabajar o pagar un tributo a su dueño, llamado encomendero, el cual por su parte tenía obligación de evangelizarlo, instruirlo en la civilización católica, apostólica y romana. Aplicado inicialmente en La Española, este sistema se extendió por toda Hispanoamérica. La codicia de los encomenderos era tal que no solamente no cumplían con la Leyes Indias sino que trataban a los indios más mal que a sus propios animales. El memorial del Bachiller Luis Sánchez, escrito en 1566 y que se encuentra en el Archivo de Indias, 
dice: "todos los daños y robos dichos -hablando de los encomenderos- $y$ cuantos se han hecho en Las Indias, los ha causado la insaciable codicia de los españoles".

Pero tal vez el texto más emblemático, contundente y decisiva denuncia del sistema encomendero lo tenemos en la Brevísima relación de la destrucción de Las Indias así como en la Historia general de Las Indias, obras polémicas escritas por el misionero dominico español Bartolomé de Las Casas, llamado "El apóstol de Las Indias" o "El protector de los indios". Desde su misión en América en 1502, combatió infatigablemente los abusos del sistema encomendero y logró su reforma provocando las Nuevas Leyes de Las Indias, en donde se atribuían nuevos derechos a los indios, no suficientes pues todavía se les consideraba jurídicamente menores de edad y socialmente salvajes. Sin, por tanto, justificar la bellaquería, la viveza tiene también una connotación crítica pues pone de manifiesto la existencia de un sistema legal pervertido. "El vivo" desprecia la ley que siempre lo ha despreciado a él por ser un pobre y un marginado, con lo cual aparece también el rasgo de revuelta en la viveza, sacándole la vuelta a la autoridad intransigente. En el abuso de poder del autoritarismo se anima la viveza criolla como gesta de sobrevivencia. La viveza criolla se agudiza en los espacios donde hay mayor fractura social, con lo cual es un síntoma de crisis agravada.

En vez de celebrar la malicia y la viveza como la única habilidad que le queda al pobre diablo, al marginado y a la gente del común, aquella sin linaje ni educación, el pícaro plebeyo -si se quiere seguir en herencia hispánica-, se requiere buscarle soluciones a las causas de la marginalización y la pobreza. La sociedad ilustrada colombiana no debería seguir aceptando que la viveza criolla sea celebrada como la ingeniosidad paisa para penetrar los mercados internacionales, tener presencia mundial e inundar de dólares mal habidos la economía local, regional y nacional. Pueda la Historia aportar a los colombianos la toma de consciencia de valores republicanos, aquellos que hacen Estado de 
Derecho y de Deberes para seguir construyendo el proceso complejo de una sociedad equitativa y competidora, atractiva, responsable y solidaria. Que esta consciencia de mente y corazón sea pues la oportunidad para darle a la imagen y al reconocimiento mundial del colombiano, como mestizo latinoamericano, otra tarjeta de identidad que la patente de corso a la bellaquería. Que no sigan siendo Colombia y los colombianos la lacra de un pueblo estigmatizado por los otros como el país por excelencia de la viveza criolla, del tráfico de drogas y de la narcoguerrilla. Que una toma de conciencia con mente y corazón sea pues la oportunidad para replantearle a la imagen y al reconocimiento mundial del colombiano otra tarjeta de identidad que no sea la patente de corsos al goce inmediato por haberes mal habidos. Que no siga siendo la imagen de Colombia en el mundo la lacra de un pueblo estigmatizado. Pueda ser que Colombia sea, de verdad, el país en donde el único peligro sea el riesgo de que te quieras quedar vivir ahora y ahí.

\section{Referencias}

Aguinis, M. (2002). El Atroz Encanto de Ser Argentino. Buenos Aires: Planeta. Anónimo. (1940). La vida de Lazarillo de Tormes y de sus fortunas y adversidades. (Victor García de la Concha, Ed.). Madrid: Espasa Calpe. Arrom, J. J. (1971). Certidumbre de América. Madrid: Editorial Gredos.

García Canclini, N. (1999). La globalización imaginada. México - Buenos Aires - Barcelona: Paidos.

Lavallé, B. (1978). Recherches sur l'apparition de la conscience créole dans la vice-royauté du Pérou : Lantagonisme hispano-créole dans les ordres religieux (XVIème - XVIIème siècles). Université Michel de Montaigne Bordeaux 3. Recuperado a partir de https://tel.archives-ouvertes.fr/tel01585336

Neira, H. (2010). Las Independencias. Doce ensayos. Lima: Nuevos Tiempos. Nuevas Ideas.

Paz, O. (1957). Lecturas de Piedra de sol. Fondo De Cultura Economica.

Scavino, D. (2010). Narraciones de la Independencia. Arqueología de un fervor contradictorio. Buenos Aires: Eterna Cadencia.

Serrano, E. (1997). La marca de España. Madrid: Alfaguara. 